\title{
Application of Time-by-Time Oral Method for the Colon Disease Patients Who Use Polyethylene Glycol Electrolytes Powder (II) Treatment Method in Electronic Colonoscopy
}

\author{
Jishi Wu ${ }^{1}$, Jinglan Luo ${ }^{2, *}$, Rui Xi ${ }^{1}$, Zhaolin Chen ${ }^{1}$ \\ ${ }^{1}$ Digestive Department, The First Affiliated Hospital of Jinan University, Guangzhou, China \\ ${ }^{2}$ Internal Medicine Department, The First Affiliated Hospital of Jinan University, Guangzhou, China \\ Email address: \\ 673046806@qq.com (Jishi Wu), tlj1@jnu.edu.cn (Jinglan Luo), 1156974221@qq.com (Rui Xi),2009gzjnu@163.com (Zhaolin Chen) \\ ${ }^{*}$ Corresponding author
}

To cite this article:

Jishi Wu, Jinglan Luo, Rui Xi, Zhaolin Chen. Application of Time-by-Time Oral Method for the Colon Disease Patients Who Use Polyethylene Glycol Electrolytes Powder (II) Treatment Method in Electronic Colonoscopy. European Journal of Clinical and Biomedical Sciences. Vol. 6, No. 2, 2020, pp. 18-21. doi: 10.11648/j.ejcbs.20200602.11

Received: March 31, 2020; Accepted: April 17, 2020; Published: April 30, 2020

\begin{abstract}
Objective: To evaluate application of Time - by - time oral method for the colon disease patients who use Polyethylene Glycol Electrolytes Powder (II) treatment method in electronic colonoscopy. Methods: 100 patients were invested to join our study from January 2019 to March 2019. They use Polyethylene Glycol Electrolytes Powder (II) treatment method in electronic colonoscopy process. They were randomly assigned to control group $(n=50)$ and intervention group ( $\mathrm{n}=50)$. In intervention group, the participants receive time - by - time oral method when they use PGEP2. The control group participants use the PGEP2 by the usual way. The collected data include patient characteristics, effective cleanliness index, adverse reaction and drug tolerance, those data from our recording. In research process, we use the special questionnaires which is Boston Bowel Preparation Scale (BBPS). Result: The two different group participants have similar patient characteristics and effective cleanliness in study result from patient characteristics research and BBPS. In addition, the intervention group has lower abdominal distension rate than that of control group in result, it is statistical significance [1 $(2 \% \mathrm{vs} 17(34 \%)$, p $<0.001]$. In addition, the intervention group patients have better drug tolerance, the result is statistical significance [50 (100\%) vs 44 (88\%), $\mathrm{p}=0.035]$. Conclusion: the time - by - time oral method is good for reduce the rate of adverse reaction, such as nausea and abdominal distension. Additionally, it can improve the drug tolerance, it shows more patients can take medicine on time in the process of using a drug.
\end{abstract}

Keywords: Colonoscopy, Nursing, Colon Disease

\section{Introduction}

Electronic colonoscopy is widely in the detection of many dis-eases, especially the screening and diagnosis of colorectal cancers. It is considered the gold standard for detecting and removing polyps and adenomas in the electronic colorectum. However, colonoscopy is accepted highly invasive, painful and uncomfortable procedure [1, 2]. Additionally, most patients will suffer the pain associated with embarrassment, fear, anxiety, and physical and emotional discomfort [3]. The main problems of electronic colonoscopy were Severe or moderate anxiety and pain in colonoscopy process, they decrease the success of the procedure and patient satisfaction.
Its negative physiological changes include increased blood pressure and heart rate. Thus, electronic colonoscopy with sedation is used to increase patient satisfaction and procedure success and to reduce anxiety and pain $[4,5]$. In recent years, in addition to pharmacological methods, nonpharmacological methods such as music, aromatherapy, hypnosis, and acupuncture are used to reduce anxiety and pain during colonoscopy [6]. in Turkey, although the report shown the influence of music therapy performed during colonoscopy on pain and anxiety, the influence of comfort was not been reported [7].

Colonoscopy provide a definitive diagnosis as well as therapeutic in-terventions to the patients. It is recommended 
by societal guidelines given its favorable safety profile [8]. In limitation, the optimal timing of inpatient colonoscopy remains controversial, and randomized trial data supporting the benefit of urgent colonoscopy is lacking in regards to its ability to improve meaningful clinical outcomes [9, 10]. In addition, the colon disease can be primary colonoscopy screening programs, in which all participants undergo a screening colonoscopy, or can be based on other modalities such as a non-invasive stool test or sigmoidos-copy, which are followed up by colonoscopy in case of a positive test result [11]. The aim of this report is to assess application of time - by - time oral method for the Colon disease patients who use Polyethylene Glycol Electrolytes Powder (II) (PGEP2) treatment method in electronic colonoscopy.

\section{Methods}

From January 2019 to March 2019, we invested 128 patients to participate in our study, but only 100 patients are meet the conditions for our research. They have similar body status, that all participants use Polyethylene Glycol Electrolytes Powder (II) treatment method in electronic colonoscopy process. They require electronic colonoscopy to ensure their colon disease situation. After they sign the informed consent contract, we randomly assign them to two different groups which have same number of people. The control group patient and intervention group patient receive different nursing service. For control group patient, they use the PGEP2 by the usual way. Our researchers record the information was associated with medication and physical condition. In intervention group, the participants receive time - by - time oral method when they use PGEP2. In time - by time oral method, PGEP2 was taken orally in two times per period, $1000 \mathrm{ml}$ each time at 6 p.m. on the day before colonoscopy and 5 a.m. on the day of colonoscopy. The collected data include patient characteristics, effective cleanliness index, adverse reaction and drug tolerance, those data from our recording. In research process, we use the special questionnaires which is Boston Bowel Preparation Scale (BBPS), it is a well-validated scale for assessing bowel preparation cleansing after standard cleansing maneuvers have been performed [12].

Their inclusion criteria were: (1) The patients were diagnosed as colon disease; (2) They use Polyethylene Glycol Electrolytes Powder (II) treatment method in electronic colonoscopy; (3) The patient sign informed consent contract. Their withdraw criteria were: (1) Patients with nausea, vomiting and abdominal distension before using PGEP2; (2) They are action inconvenience; (3) They have gastric cancer, undergoing gastric surgery and constipation.

In statistical analysis, our data analyzer performed the statistical analysis by SPSS 24.0. The P value, t-test and chi-square test were associated with collection result were analyzed. Besides, the mean standard deviation for statistical description.

\section{Result}

The Table 1 shows the patient characteristics of two different groups. In control group and intervention group, the participants have similar age situation and gender situation. Additionally, the effective clean status of two group are same in our research, the rates of effective clean are $98 \%$ in control group and intervention group. The data of 3 parts are not statistical significance, it means that the patient characteristics of two group participants are similar.

Table 1. Patient Characteristics.

\begin{tabular}{llll}
\hline Projects & Age (year) & Male, n (\%) & Female, n (\%) \\
\hline Intervention Group $(\mathrm{n}=50)$ & $54.80 \pm 11.189$ & $21(42 \%)$ & $29(58 \%)$ \\
Control Group $(\mathrm{n}=50)$ & $54.42 \pm 12.814$ & $26(52 \%)$ & $24(48 \%)$ \\
T & 1.72 & 1.004 & $49(98 \%)$ \\
P Value & 0.864 & 0.316 & $49(98 \%)$ \\
\hline
\end{tabular}

About assessment of BBPS, the invalid cleaning is 0 points and 1 point. Also, effective cleaning is 2 points and 3 points. Overall, the participants of 2 score have more people than that of 3 score in every domain. All $p$ values are higher than 0.05 , it shows that they are similar in every domain $(\mathrm{p}=0.638 \&$ $\mathrm{p}=0.836 \& \mathrm{p}=0.671)$.

Table 2. Effective cleanliness of different segments from BBPS.

\begin{tabular}{|c|c|c|c|c|c|c|}
\hline \multirow{2}{*}{ Projects } & \multicolumn{2}{|c|}{ left hemicolon, n (\%) } & \multicolumn{2}{|c|}{ colon transversum, n (\%) } & \multicolumn{2}{|c|}{ Right hemicolon, n (\%) } \\
\hline & 2 score & 3 score & 2 score & 3 score & 2 score & 3 score \\
\hline Intervention group $(n=50)$ & $38(77.6 \%)$ & $11(22.4 \%)$ & $29(59.2 \%)$ & $20(40.8 \%)$ & $31(63.3 \%)$ & $18(36.7 \%)$ \\
\hline Control group $(\mathrm{n}=50)$ & $36(73.5 \%)$ & $13(26.5 \%)$ & $30(61.2 \%)$ & $19(38.8 \%)$ & $33(67.3 \%)$ & $16(32.7 \%)$ \\
\hline $\mathrm{X}^{2}$ & 0.221 & & 0.43 & & 0.18 & \\
\hline P Value & 0.638 & & 0.836 & & 0.671 & \\
\hline
\end{tabular}

In Table 3, the control group has more participants who have adverse reaction in the course of medication, and intervention group has higher drug tolerance (100\% vs $88 \%)$. In particular, the intervention group has lower abdominal distension rate than that of control group in result, it is statistical significance [1 (2\% vs $17(34 \%), \mathrm{p}<0.001]$. In addition, the intervention group patients have better drug tolerance, the result is statistical significance [50 (100\%) vs 44 $(88 \%), p=0.035]$. 
Table 3. Rate of adverse reaction and drug tolerance.

\begin{tabular}{|c|c|c|c|c|c|}
\hline Projects & Nausea, n (\%) & vomiting, n (\%) & $\begin{array}{l}\text { Abdominal } \\
\text { distension, n (\%) }\end{array}$ & Affect sleep, n (\%) & $\begin{array}{l}\text { Whether to take medicine } \\
\text { on time, n }(\%)\end{array}$ \\
\hline Intervention group $(n=50)$ & $3(6 \%)$ & $0(0 \%)$ & $1(2 \%)$ & $4(8 \%)$ & $50(100 \%)$ \\
\hline Control group $(n=50)$ & $16(32 \%)$ & $1(2 \%)$ & $17(34 \%)$ & $0(0 \%)$ & $44(88 \%)$ \\
\hline $\mathrm{X}^{2}$ & 10.981 & 1.396 & 17.344 & 2.344 & 4.433 \\
\hline $\mathrm{P}$ Value & 0.001 & 0.237 & $<0.001$ & 0.126 & 0.035 \\
\hline
\end{tabular}

\section{Discussion}

Colonoscopy is one of the most frequently performed invasive medical procedures, it is Widely utilized for the screening, diagnosis, and treatment of colorectal disease. In the United States, the report showed more than 11.5 million colonoscopies are performed every year, the number is continuously increase as the population ages [13]. Although colonoscopy is considered a safe medical measure, it still had mortality every that the estimated mortality rate was 2.9 per 100,000 procedures [14]. Furthermore, although life-threatening complications are rare, colonoscopy is not a benign procedure. The most common serious complications of colonoscopy are bleeding and perforation of the colon [15]. Additionally, colonoscopy-associated splenic rupture was rare but life-threatening complications in colonoscopies [16]. So well recognized complications include perforation, bleeding, post-polypectomy syndrome and side effects related to sedation and analgesia. Base on some reports, there are also a number of rare complications reported in the literature including splenic trauma, infection, diverticulitis and appendicitis [17].

According to above result, the time - by - time oral method is good for reduce the rate of adverse reaction, such as nausea and abdominal distension. Additionally, it can improve the drug tolerance, it shows more patients can take medicine on time in the process of using a drug. However, intervention group patients have worse affect sleep situation after the new nursing services. The researches of patient characteristics and the BBPS assessment shows the two different group participants have similar patient characteristics and effective cleanliness in study result. Thus, the participants situation of two groups are similar, it excludes most of the additional factors which can influence the veracity of this study result. The influence of the time - by - time oral method was showed in rate of adverse reaction and drug tolerance, the intervention group participants easier to accept PGEP2 treatment. Compare with control group, the research result of the rate of adverse reaction and drug tolerance shows that the number participants who had nausea or abdominal distension have significant reduction.

\section{References}

[1] Tinmouth J, Kennedy EB, Baron D, Burke M, Feinberg S, Gould $\mathrm{M}$, et al. Colonoscopy quality assurance in Ontario: systematic review and clinical practice guideline, Chin. J. Gastroenterol. Hepatol. 2017; 28 (5): 251-274.
[2] Leung FW. Methods of reducing discomfort during colonoscopy, Dig. Dis. Sci. 2018; 53 (6): 1462-1467.

[3] Sargin M, Uluer MS, Aydogan E, Hanedan BMI, Tepe MA, Eryılmaz EE, et al. Anxiety levels in patients undergoing sedation for elective upper gastrointestinal endoscopy and colonoscopy, Med. Arch. 2016; 70 (2): 112-115.

[4] Yang C, Sriranjan V, Abou-Setta AM, Poluha W, Walker JR, Singh H. Anxiety associated with colonoscopy and flexible sigmoidoscopy: a systematic review, Am. J. Gastroenterol. 2018; 113 (12): 1810-1818.

[5] Lee E, Shafer LA, Walker JR, Waldman C, Michaud V, Yang C, et al., Information experiences, needs, and preferences of colonoscopy patients, Medicine (Baltim.) 2019; 98 (20): 15738.

[6] Ueki S, Matsunaka E, Swa T, Ohashi K, Makimoto K. Effectiveness of inhalation of aromatherapy in reducing anxiety in patients before colonoscopy: a systematic review protocol, JBI. Database Syst. Rev. Implement. Rep. 2015; 13 (9): 40-50.

[7] Ovayolu N, Pehlivan S, Pehlivan Y, Buyukhatipoglu HM, Savas MC. Listening to Turkish classical music decreases patients' anxiety, pain, dissatisfaction and the dose of sedative and analgesic drugs during colonoscopy: a prospective randomized controlled trial, World J. Gastroenterol. 2014; 12 (46): 7532-7536.

[8] Strate LL, Ayanian JZ, Kotler G, Syngal S. Risk factors for mortality in lower intestinal bleeding. Clin Gastroenterol Hepatol. 2018; 6 (9): 1004-1410.

[9] Sengupta N, Tapper EB, Patwardhan VR, Ketwaroo GA, Thaker AM, Leffler DA, et al. Risk factors for adverse outcomes in patients hospitalized with lower gastrointestinal bleeding. Mayo Clin Proc 2015; 90 (8): 1021-1029.

[10] Gralnek IM, Ron-Tal Fisher O, Holub JL, Eisen GM. The role of colonoscopy in evaluating hematochezia: a population-based study in a large consortium of endoscopy practices. Gastrointest Endosc 2013; 77 (3): 410-418.

[11] Schreuders EH, Ruco A, Rabeneck L, et al. Colorectal cancer screening: a global overview of existing programmes. Gut 2015; 64: $1637-49$.

[12] Lai EJ, Calderwood AH, Doros G, et al. The Boston Bowel Preparation Scale: a valid and reliable instrument for colonoscopy-oriented research. Gastrointest Endosc 2009; 69: $620-5$.

[13] Peery AF, Dellon ES, Lund J, et al. Burden of gastrointestinal disease inthe United States: 2012 update. Gastroenterology 2016; 143: 1179-1187.

[14] Reumkens A, Rondagh EJ, Bakker CM, Winkens B, Masclee AA, Sanduleanu S. Post-colonoscopy complications: a systematic re-view, time trends, and meta-analysis of population-based studies. Am J Gastroenterol 2016; 111: $1092-101$. 
[15] Ko CW, Dominitz JA. Complications of colonoscopy: magnitude and management. Gastrointest Endosc Clin N Am 2017; 20: 659-71.

[16] Jehangir A, Poudel DR, Masand-Rai A, Donato A. A systematic re-view of splenic injuries during colonoscopies: evolving trends in presentation and management. Int J Surg 2016; 33: 55-59.
[17] Salim A, Sangthong B, Martin M, Brown C, Plurad D, Demetriades D. Whole body imaging in blunt multisystem trauma patients without obvious signs of injury: results of a prospective study. Arch Surg 2016; 141: 468-473. 